\title{
Selection of potential probiotic lactobacilli for cholesterol-lowering properties and their effect on cholesterol metabolism in rats fed a high-lipid diet
}

\author{
J. Wang, H. Zhang, ${ }^{1}$ X. Chen, Y. Chen, Menghebilige, and Q. Bao \\ The Key Laboratory of Dairy Biotechnology and Bioengineering, Education Ministry of P. R. China, Department of Food Science and Engineering, \\ Inner Mongolia Agricultural University, Huhhot 010018, P. R. China
}

\begin{abstract}
The objectives of this study were to screen probiotic characteristics of lactobacilli isolated from traditionally homemade koumiss products in Xinjiang and Inner Mongolia of China, and to determine and compare the effect of the Lactobacillus strains in vivo on lipid metabolism in rats fed with a high-lipid diet. Three out of 68 strains of Lactobacillus isolated from the koumiss were screened for bile-salt resistance, acid tolerance, and different hypocholesterolemic properties. The cholesterol-lowering effects of the 3 screened strains were estimated in rats fed a high-lipid diet by determination of serum lipids, liver, and fecal cholesterol, fecal total bile acids, and short-chain fatty acids. After a 4-wk feeding period, in comparison with the control group, the groups LIP-1 and MG9-2 had a significant reduction in serum total cholesterol, triglyceride and low-density lipoprotein cholesterol, and significantly increased high-density lipoprotein, the group E7301 had similar effects on serum lipids, but the change was not significant. The groups LIP-1, MG9-2 and E7301 had a significant reduction in liver cholesterol content and an increase in fecal cholesterol content compared with the control group. Total bile acid excretion was significantly higher in rats fed MG9-2 than the other groups. Rats fed diets containing lactic acid bacteria strains had significantly higher propionic acid and butyric acid concentrations in the feces compared with the control. Results indicated that the 3 screened Lactobacillus strains were able to lower cholesterol in vitro, and reduce cholesterol effectively in vivo. The mechanisms behind the hypocholesterolemic effect of 3 strains are likely to be diverse and will need further investigation. Key words: Lactobacillus, cholesterol-lowering effect, probiotic, koumiss
\end{abstract}

Received July 26, 2011.

Accepted December 5, 2011.

${ }^{1}$ Corresponding author: hepingdd@vip.sina.com

\section{INTRODUCTION}

Coronary heart disease (CHD) is the main cause of death in China, and many other countries around the world (Liu, 2007). The World Health Organization (WHO) has predicted that by 2030, cardiovascular disease will remain the leading cause of death, affecting approximately 23.6 million people (WHO, 2009). One of the major risk factors for CHD is hypercholesterolemia (Fradi et al., 2008). The higher the serum total cholesterol or low-density lipoprotein (LDL) cholesterol, the greater the risk that CHD will develop. Although drug therapies effectively decrease cholesterol levels, they are expensive and can have severe side effects (Bliznakov, 2002). A need exists to focus on the scientific exploration of natural food products that may be able to lower serum cholesterol level extensively with few or no side effects.

In recent years, the probiotic activity of lactic acid bacteria (LAB) has been studied. Probiotics are live microbial feed supplements that beneficially affect the host animal by improving its intestinal microbial balance (Fuller, 1992). One of the beneficial health effects related to probiotics is their ability to reduce serum cholesterol levels (Grunewald, 1982; Lye et al., 2010a,b).

There is a continuing interest in development of effective natural ingredients from food (e.g., certain cultured dairy products or culture-containing dairy foods supplemented with Lactobacillus acidophilus) that could decrease concentrations of serum cholesterol (Tortuero et al., 1975; Grunewald, 1982; Gilliland et al., 1985; Danielson et al., 1989; Lye et al., 2010a,b). Many other different kinds of Lactobacillus cultures also exerted a hypocholesterolemic effect (Nielson and Gilliland, 1985; Fukushima and Nakao, 1995; Taranto et al., 1998; Usman and Hosono, 2000; Liong and Shah, 2006).

Several mechanisms have been hypothesized to explain these findings, which include enzymatic deconjugation of bile acids by bile salt hydrolase of probiotics (Begley et al., 2006; Lambert et al., 2008), assimilation of cholesterol by probiotics (Bottazzi et al., 1986), co-precipitation of cholesterol with deconjugated bile (Liong and Shah, 2006), cholesterol binding to cell 
walls of probiotics (Hosono and Tonooka, 1995), incorporation of cholesterol into the cellular membranes of probiotics during growth (Lye et al., 2010b), conversion of cholesterol into coprostanol (Lye et al., 2010a), and production of short-chain FA (SCFA) upon fermentation by probiotics (Tabuchi et al., 2004). Most of the hypotheses raised to date are based on in vitro experiments, and few attempts have been made to evaluate the possible hypocholesterolemic mechanisms based on in vivo trials.

Koumiss is a very popular naturally fermented dairy product for the people of Mongolia, Kazakhstan, Kirgizstan, and some regions of Russia. In Inner Mongolia, koumiss therapy was developed combining traditional medicine with koumiss to assist treatment (Hasisurong et al., 2003). Favorable influences on the control of serum cholesterol, alimentary canal activity, the circulatory and nervous systems, blood-forming organs, kidney functions, liver disease, endocrine glands, and the immune system have been reported (Tsenina and Frolov, 1980; Suzuki and Kajuu, 1983; Stoianova et al., 1988; Fedechko et al., 1995; Hasisurong et al., 2003).

The aim of this study was to screen lactobacilli with probiotic characteristics isolated from traditionally homemade koumiss, and to determine and compare the effect of the screened Lactobacillus strains on lipid metabolism in rats fed a high-lipid diet. Moreover the possible mechanisms by which these strains might exert their hypocholesterolemic effects in vivo trials were also explored.

\section{MATERIALS AND METHODS}

\section{Source and Maintenance of Cultures}

Sixty-eight Lactobacillus strains were obtained from Key Laboratory of Dairy Biotechnology and Engineering Ministry of Education (Inner Mongolia Agricultural University, Huhhot, P. R. China), which were all isolated from homemade koumiss products in Xinjiang and Inner Mongolia of China. These cultures were maintained by inoculation $(2 \%, \mathrm{vol} / \mathrm{vol})$ in de Man, Rogosa, and Sharpe (MRS) broth (Difco, Mississauga, ON, Canada) and incubating them for $18 \mathrm{~h}$ at $37^{\circ} \mathrm{C}$. The cultures were stored at $4^{\circ} \mathrm{C}$ between transfers and were subcultured 1 time before use.

\section{Tolerance to Simulated Gastric Juice}

To determine the tolerance through simulated gastric juice, the method of Vinderola and Reinheimer (2003) was used with slight modifications. Fifty milliliters of MRS broth was inoculated at $2 \%$ (vol/vol) with Lactobacillus strains and incubated at $37^{\circ} \mathrm{C}$ for $18 \mathrm{~h}$; then, cultures were centrifuged $\left(6,000 \times g\right.$ for $20 \mathrm{~min}$ at $\left.5^{\circ} \mathrm{C}\right)$, washed twice in $50 \mathrm{mmol} / \mathrm{L} \mathrm{K}_{2} \mathrm{HPO}_{4}(\mathrm{pH} 6.5)$ and resuspended in $5 \mathrm{~mL}$ of the same buffer. One milliliter of washed cell suspension was harvested by centrifugation $\left(12,000 \times g\right.$ for 5 min at $\left.5^{\circ} \mathrm{C}\right)$ and resuspended in $10 \mathrm{~mL}$ of artificial gastric juice with the following composition: $5 \mathrm{~g}$ of $\mathrm{NaCl} / \mathrm{L}$ and $3 \mathrm{~g}$ of pepsin/L. The final $\mathrm{pH}$ was adjusted with $\mathrm{HCl}$ to $\mathrm{pH} 3$. A 1-mL sample was taken before and after an incubation period of $3 \mathrm{~h}$, and 10-fold serial dilutions were made using peptone water diluent. Samples were plated onto MRS agar, and the plates were incubated at $37^{\circ} \mathrm{C}$ for $24 \mathrm{~h}$ under anaerobic conditions. The results were expressed as the percentage survival by comparing the final plate count after 3 $\mathrm{h}$ with the initial plate count at $0 \mathrm{~h}$. The strains with survival rates in gastric juice at $\mathrm{pH} 3.0$ of more than $10 \%$ were selected for further study.

\section{Bile Resistance}

The ability of the strains to grow in the presence of bile was determined according to the method of Vinderola and Reinheimer (2003). Each strain was inoculated $(2 \%, \mathrm{vol} / \mathrm{vol}$ ) in MRS broth with $0.3,0.5$, or $1 \%$ (wt/ vol) of oxgall (Difco). Cultures were incubated at $37^{\circ} \mathrm{C}$, and after $24 \mathrm{~h}$, absorbance at $560 \mathrm{~nm}$ was measured and compared with a control culture (without bile salts). The results were expressed as the percentage of growth in the presence of bile salts compared with the control.

\section{Assimilation of Cholesterol}

The ability of cultures to assimilate cholesterol was determined by a modification of the method described by Danielson et al. (1989). Each freshly prepared strain culture was inoculated (1\%) in $10 \mathrm{~mL}$ of MRS broth supplemented with $0.2 \%$ sodium thioglycollate (Sigma Chemical Co., St. Louis, MO), $0.3 \%$ oxgall (Difco), and a water-soluble form of cholesterol (polyoxyethanyl-cholesteryl sebacate; Sigma Chemical Co.). The final concentration of cholesterol in the broth was approximately $100 \mu / \mathrm{mL}$. The tubes were incubated at $37^{\circ} \mathrm{C}$ for $20 \mathrm{~h}$. After incubation, cells were removed by centrifugation for $10 \mathrm{~min}$ at $12,000 \times g$ and $4^{\circ} \mathrm{C}$. The $o$-phthalaldehyde method for measuring cholesterol described by Rudel and Morris (1973) was used to determine the amount of cholesterol in the spent broth and uninoculated sterile broth.

\section{Feeding Trial}

Lactobacillus Strains. Stock strains were anaerobically cultured in MRS broth at $37^{\circ} \mathrm{C}$ for $18 \mathrm{~h}$; the cells were harvested by centrifugation $(6,000 \times g$ for 
10 min at $5^{\circ} \mathrm{C}$ ) and washed 3 times with a sterile saline solution. The cell pellets were then resuspended in $10 \%$ sterile skim milk at $2 \times 10^{9} \mathrm{cfu} / \mathrm{mL}$ concentration. Cell numbers were confirmed by plating anaerobically onto MRS agar plates at $37^{\circ} \mathrm{C}$ for $48 \mathrm{~h}$. The cultures were stored for no more than $30 \mathrm{~d}$ at $-80^{\circ} \mathrm{C}$ before use.

Grouping of Animals and Diets. Five-week-old male Wistar rats were purchased from the Experimental Animal Breeding Laboratory of Inner Mongolia University (Hohhot, China). The animals were maintained in accordance with the guidelines of the Ethical Committee for Animal Experiments of Inner Mongolia University. All animals were housed individually in cages and maintained on a 12-h light-dark cycle. Temperature and humidity were controlled at 20 to $22^{\circ} \mathrm{C}$ and 60 to $65 \%$, respectively. The rats were allowed free access to water and fed for the first week with a commercially prepared pelleted diet for adjustment. The rats were then randomly divided into 4 groups of 8 animals. No significant differences in BW existed between groups at the start of the experimental period [the average initial BW (g) were 135 (SD 15), 136 (SD 11), 138 (SD 13), and 137 (SD 16), respectively, for the 4 experimental groups]. They were fed on either a high-fat and high-cholesterol diet (control group), or a high-fat and high-cholesterol diet supplemented with different LAB strains for $4 \mathrm{wk}$. With a sterile pipette, 3 of the groups were orally inoculated with 1 of the 3 screened LAB strains at the same doses, whereas the fourth (control) group was orally administered $10 \%$ skim milk only. Two milliliters of cell suspensions in $10 \%$ skim milk, or $10 \%$ skim milk was administrated at each inoculation so that each rat in the treatment groups received $4 \times 10^{9} \mathrm{cfu}$ per day. The composition of the fat and cholesterol-enriched diet was (g/100 g) casein, 20; corn starch, 43; lard, 10; cholesterol, 1; cellulose, 2; vitamin mixture (AIN-93; American Institute of Nutrition, Bethesda, MD), 1; mineral mixture (AIN-93; American Institute of Nutrition), 3.5; sodium cholate, 0.20 ; and sucrose, 100 .

Sample Collection. Food intake was recorded daily and BW at the beginning and end of the study. Fecal samples were collected for the last $3 \mathrm{~d}$, freeze dried, and then stored at $-20^{\circ} \mathrm{C}$ until analyzed. At the end of the 4-wk feeding trial, rats were fasted overnight, and anesthetized by diethyl ether. Blood samples were collected immediately in sterile tubes by heart puncture. Blood samples were centrifuged $\left(1,480 \times g\right.$ for $20 \mathrm{~min}$ at $\left.4^{\circ} \mathrm{C}\right)$, and the serum was separated and stored at $-20^{\circ} \mathrm{C}$ until analyzed. The spleen, liver, and kidneys were removed immediately, rinsed with cold saline, and weighed, and the liver was frozen in liquid nitrogen and stored at $-80^{\circ} \mathrm{C}$ for later estimation of lipids.
Analytical Methods. The concentrations of total cholesterol, high-density lipoprotein (HDL) cholesterol, and triglycerides in the serum were measured using enzymatic colorimetric methods with commercial kits (Wako Pure Chemical Industries Ltd., Osaka, Japan) and a photometric autoanalyzer (7510; Hitachi, Tokyo, Japan). Serum LDL cholesterol levels were calculated using the formula developed by Friedewald et al. (1972). After liver and fecal samples were extracted with chloroform-methanol (2:1) solvent, liver and fecal cholesterol concentrations were determined using the same kits as for the serum (Folch et al., 1957). Bile acids were extracted from dried feces using organic solvents (Locket and Gallaher, 1989) and the extracted solutions were used to determine total bile acid concentration (Randox Chemical, Antrim, United Kingdom) enzymatically by the method of Mashige et al. (1981). The concentrations of acetate, propionate, and butyrate in feces were determined using HPLC (Agilent 1100; Agilent Technologies Inc., Santa Clara, CA). Samples were prepared as described previously (Tabuchi et al., 2004) with slight modifications. Two hundred milligrams of lyophilized sample was suspended in $2 \mathrm{~mL}$ of distilled water; the mixture was centrifuged $(3,000 \times g$ for $10 \mathrm{~min}$ at $4^{\circ} \mathrm{C}$ ), and an equal volume of chloroform was added to the supernatant for deproteinization, followed by centrifugation for $10 \mathrm{~min}$ at $8,000 \times g$ at $4^{\circ} \mathrm{C}$. Short-chain FA in the supernatant were measured by HPLC. The HPLC system was equipped with a multiwavelength fluorescence detector set at $220 \mathrm{~nm}$. An Agilent Zorbax SB C18 column was maintained at $65^{\circ} \mathrm{C}$ and the degassed mobile phase $(0.025 \mathrm{M}$ orthophosphoric acid) was used at a flow rate of $0.6 \mathrm{~mL} / \mathrm{min}$.

\section{Statistical Analysis}

The data analysis was carried out using SPSS Inc. (Chicago, IL) software (version 10.0). The significance of differences in response to diet was analyzed statistically by ANOVA. A difference of $P<0.05$ was considered significant. All data are presented as means \pm standard errors of means.

\section{RESULTS}

\section{Resistance to Biological Barriers and Ability to Assimilate Cholesterol}

The survival rates after exposure to simulated gastric juice, growth in the presence of bile salts and ability to assimilate cholesterol for 68 strains of Lactobacillus are shown in Table 1. All strains showed varying levels of resistance to biological barriers and ability to assimilate cholesterol. Of these strains, the 3 strains (MG9-2, LIP- 
Table 1. Resistance to biological barriers and ability to assimilate cholesterol for 68 strains of Lactobacillus $^{1}$

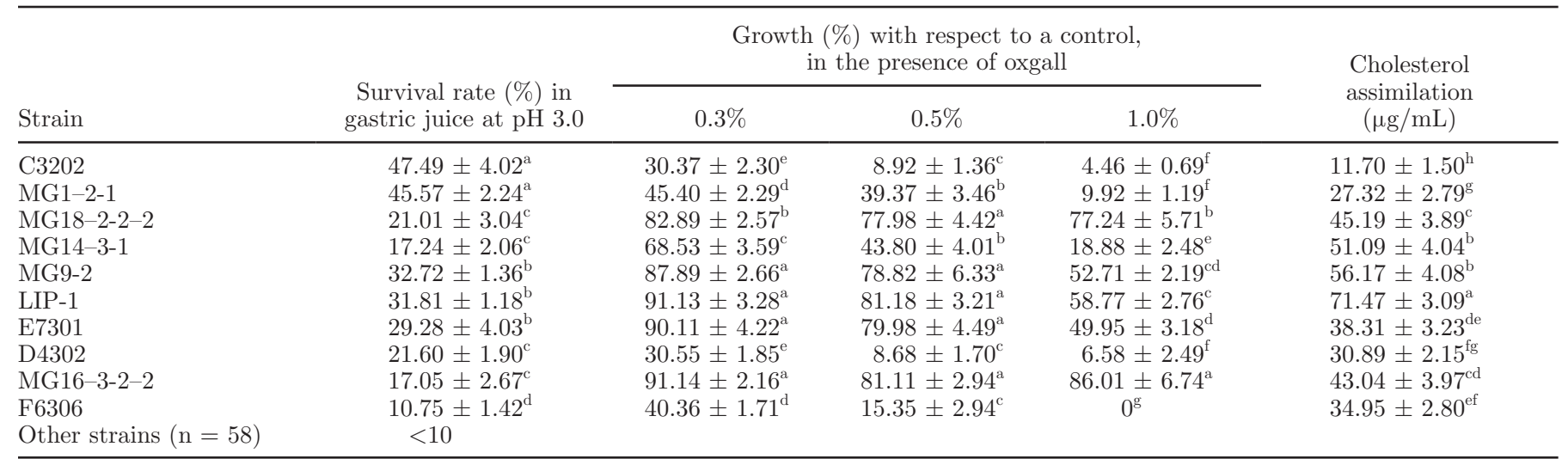

${ }^{\mathrm{a}-\mathrm{h}}$ Means within the same column followed by different superscript letters are significantly different $(P<0.05)$.

${ }^{1}$ Values are expressed as means \pm standard errors of the means; values are the means of 3 replications.

1, and E7301), which displayed similar low pH tolerance and bile-salt resistance and different hypocholesterolemic properties, were selected for further studies. The LIP-1, MG9-2 and E7301 strains were identified as Lactobacillus plantarum, Lactobacillus helveticus, and Lactobacillus fermentum, respectively, by analysis of 16S rRNA sequences, with GenBank (http://www. ncbi.nlm.nih.gov/sites/entrez?db=nucleotide) accession numbers EU213062, EU688979, and EU130908, respectively.

Of the 3 strains, MG9-2 showed higher resistance to simulated gastric juice than the others, but the differences were not significant $(P>0.05)$. The 3 strains showed strong resistance to $0.3 \%$ and $0.5 \%$ bile salt. They survived well in the presence of $1 \%$ bile salts. Strain LIP-1 grew significantly $(P<0.05)$ better than the other strains at $1 \%$ bile salts.

Variance among the 3 strains in the ability to assimilate cholesterol was significant $(P<0.05)$. The amounts of cholesterol assimilated ranged from 71.47 to 38.31 $\mu \mathrm{g} / \mathrm{mL}$. Strain LIP-1 exhibited the highest amounts of cholesterol assimilated, followed by MG 9-2 and E7301.

\section{Food Intake, Weight Gain, and Organ Weight}

Body weight gain, food intake, and the food efficiency ratio did not appear to be influenced by LAB strain supplementation (Table 2). The food efficiency ratio of LAB groups tended to be higher than the control group, but the differences were not significant $(P$ $>0.05)$. The organ weights were not found to differ among the groups.

\section{Serum Lipid Profiles}

Serum total cholesterol, triglycerides, HDL, and LDL cholesterol levels of rats fed the control, LIP-1, MG9-2, and E7301 diets are shown in Figure 1. Rats fed the LIP-1, the MG9-2, and the E7301 diets had significantly $(P<0.05)$ lower total cholesterol levels compared with the control group. Groups LIP-1 and MG9-2 had significantly lower cholesterol levels than group E7301. Groups LIP-1 and MG9-2 showed a greater reduction in triglyceride content compared with the control and E7301 groups. Group LIP-1 had the lowest triglyceride

Table 2. Food intake, weight gain, food efficiency ratio, and organ weights of rats fed a high-lipid diet alone (control) or supplemented with different lactic acid bacteria strains (LIP-1, MG9-2, or E7301) for $4 \mathrm{wk}^{1}$

\begin{tabular}{|c|c|c|c|c|}
\hline Item & Control & \multicolumn{3}{|c|}{ Treatment group } \\
\hline BW gain, 4 wk (g) & $141.0 \pm 8.5^{\mathrm{a}}$ & $143.1 \pm 13.6^{\mathrm{a}}$ & $139.8 \pm 16.9^{\mathrm{a}}$ & $144.3 \pm 8.0^{\mathrm{a}}$ \\
\hline Food efficiency ratio $(\%)$ & $29.3 \pm 2.1^{\mathrm{a}}$ & $31.6 \pm 1.1^{\mathrm{a}}$ & $31.3 \pm 2.8^{\mathrm{a}}$ & $32.3 \pm 0.6^{\mathrm{a}}$ \\
\hline \multicolumn{5}{|c|}{ Organ weight $(\mathrm{g} / 100 \mathrm{~g}$ of $\mathrm{BW})$} \\
\hline Liver & $4.44 \pm 0.31^{\mathrm{a}}$ & $4.51 \pm 0.35^{\mathrm{a}}$ & $4.28 \pm 0.25^{\mathrm{a}}$ & $4.20 \pm 0.25^{\mathrm{a}}$ \\
\hline
\end{tabular}

${ }^{a}$ Means within the same row followed by different superscript letters are significantly different $(P<0.05)$.

${ }^{1}$ Values are expressed as means \pm standard errors of the means; $\mathrm{n}=8$.

${ }^{2}$ Food efficiency ratio $(\%)=($ BW gain $/$ food intake $) \times 100$. 
Table 3. Total cholesterol levels in liver and feces of rats fed a high-lipid diet alone (control) or supplemented with different lactic acid bacteria strains (LIP-1, MG9-2, or E7301) for $4 \mathrm{wk}^{1}$

\begin{tabular}{lcccc}
\hline & & \multicolumn{2}{c}{ Treatment group } \\
\cline { 3 - 5 } Item & Control & LIP-1 & MG9-2 & E7301 \\
\hline Liver cholesterol ( $\mu$ mol/g of wet wt) & $60.20 \pm 2.45^{\mathrm{a}}$ & $49.56 \pm 2.75^{\mathrm{b}}$ & $51.20 \pm 5.96^{\mathrm{b}}$ & $53.94 \pm 4.23^{\mathrm{b}}$ \\
Fecal cholesterol $(\mu \mathrm{mol} / \mathrm{g}$ of dry wt) & $59.22 \pm 3.93^{\mathrm{c}}$ & $73.75 \pm 3.52^{\mathrm{a}}$ & $69.78 \pm 5.67^{\mathrm{ab}}$ & $67.36 \pm 6.00^{\mathrm{b}}$ \\
\hline
\end{tabular}

${ }^{\mathrm{a}-\mathrm{c}}$ Means within the same row followed by different superscript letters are significantly different $(P<0.05)$.

${ }^{1}$ Values are expressed as means \pm standard errors of the means; $\mathrm{n}=8$.

content. Group MG9-2 expressed the lowest LDL-C concentration, followed by group LIP-1 and then by the E7301 and control groups. The differences between the 4 groups were significant. The HDL-C concentrations in groups LIP-1 and MG9-2 were significantly higher than in the control and E7301 groups.

\section{Liver and Fecal Cholesterol}

Table 3 shows liver and fecal cholesterol level. Groups LIP-1, MG9-2, and E7301 had a greater reduction in liver cholesterol content compared with the control group $(P<0.05)$. Group LIP-1 had the lowest cholesterol content. The group ranking in liver cholesterol content was control $>$ E7301 > MG9-2 > LIP-1. The fecal cholesterol concentration of rats fed LAB strains increased compared with the control group $(P<0.05)$. Groups LIP-1 and MG9-2 showed higher cholesterol concentrations than did group E7301, and group LIP-1 excreted the most cholesterol in feces.

\section{Fecal Total Bile Acid Excretions}

Figure 2 shows fecal total bile acid excretions in rats. Fecal total bile acid excretion was significantly $(P<$ 0.05) higher in rats fed MG9-2 than the other groups. Fecal total bile acid excretion among the control, LIP1, and E7301 groups was similar.

\section{Fecal SCFA}

Compared with the control, the administration of 3 strains increased production of fecal SCFA. Concentrations of acetic acid were not significantly different among groups (Table 4). Rats fed diets containing LAB strains had significantly greater propionic acid and bu-

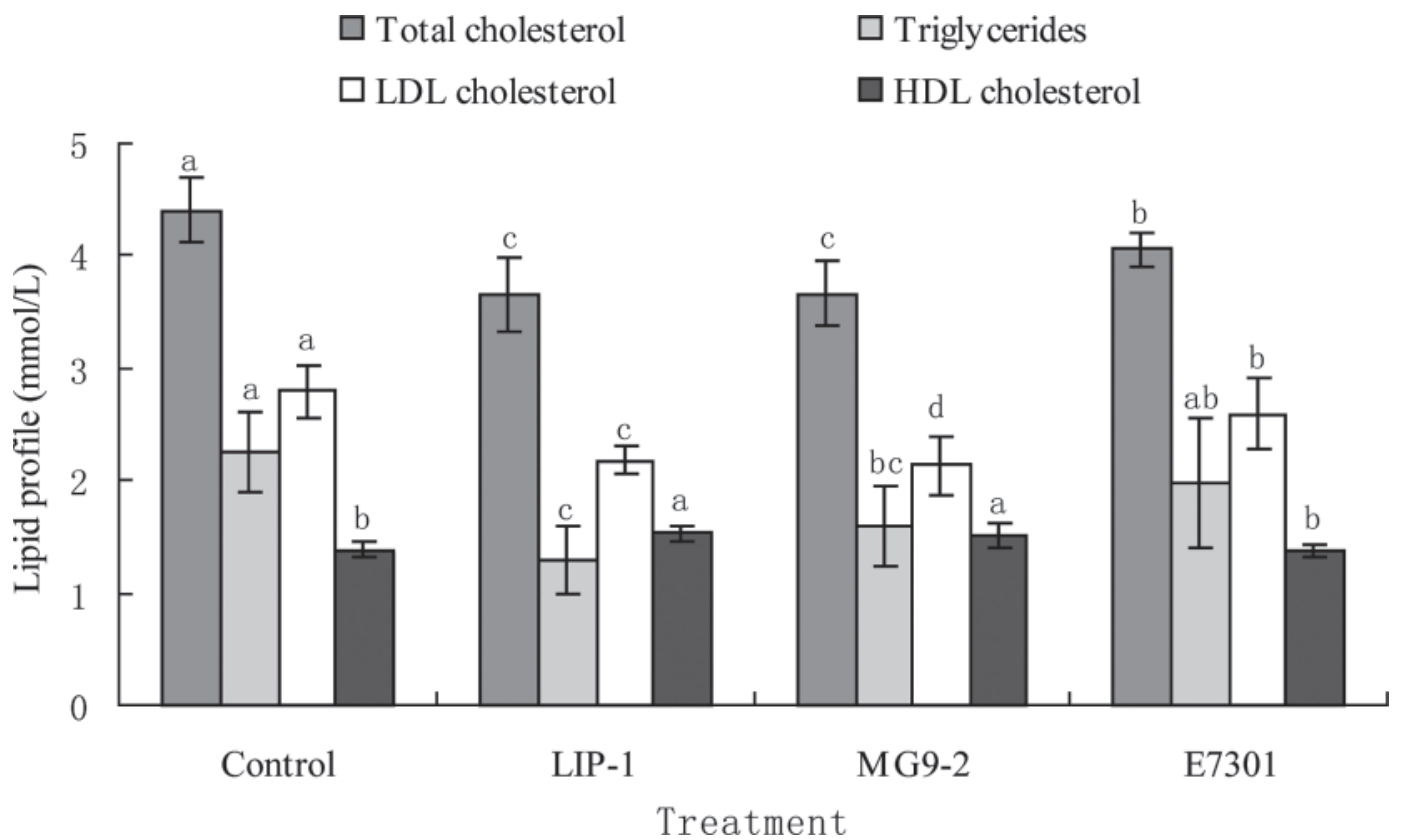

Figure 1. Total cholesterol, triglycerides, high-density lipoprotein (HDL) cholesterol, and low-density lipoprotein (LDL) cholesterol levels in serum of rats fed a high-lipid diet alone (control) or supplemented with different lactic acid bacteria strains (LIP-1, MG9-2, or E7301) for 4 wk. Results are expressed as means \pm standard errors of the means; $\mathrm{n}=8$. Means within the same lipid series with different lowercase letters (a-d) are significantly different $(P<0.05)$. 


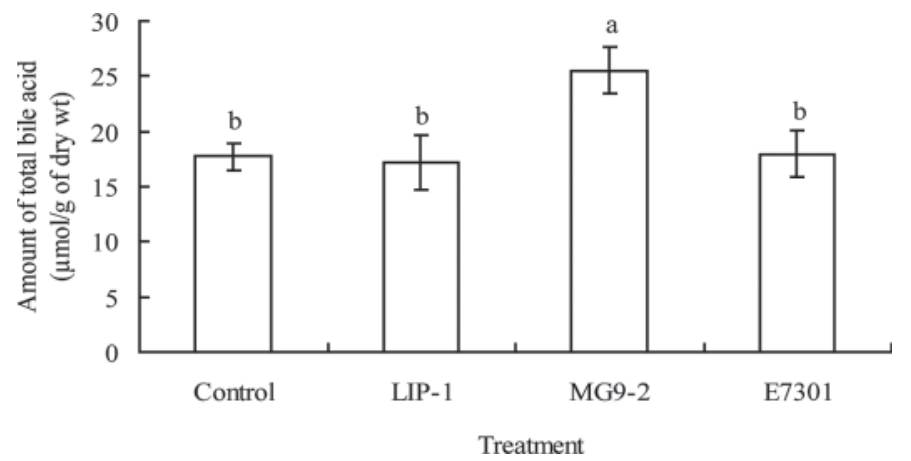

Figure 2. Fecal total bile acid excretions in rats fed a high-lipid diet alone (control) or supplemented with different lactic acid bacteria strains (LIP-1, MG9-2, or E7301) for 4 wk. Results are expressed as means \pm standard errors of the means; $\mathrm{n}=8$. Mean values with different letters $(\mathrm{a}, \mathrm{b})$ are significantly different $(P<0.05)$.

tyric acid concentrations in the feces compared with the control $(P<0.05)$. Groups MG9-2 and LIP-1 showed higher propionic acid and butyric acid concentrations than did group E7301. Group MG9-2 had the highest fecal propionic acid concentration.

\section{DISCUSSION}

High concentrations of total cholesterol and LDL cholesterol are strongly associated with an increased risk of CHD. Reduction in total cholesterol and LDL cholesterol in hypercholesterolemic men reduces the incidence of cardiovascular disease (Bliznakov, 2002; Fradi et al., 2008). Modification of diets, such as supplementation of diet with fermented dairy products or LAB-containing dairy foods may decrease serum cholesterol concentrations. The use of probiotic bacteria in decreasing serum cholesterol levels has attracted much attention.

The term probiotics refers to live microorganisms that survive passage through the gastrointestinal tract and have beneficial effects on the host. So, acid and bile tolerance is considered to be an important characteristic of probiotics that enable them to survive, to grow, and to exert action in the intestinal tract (Hood and Zottola, 1988). A significant relationship between the ability of lactobacilli to assimilate cholesterol from laboratory media and their hypocholesterolemic effect in vivo has been reported by Gilliland and colleagues (1985). A strain that did not assimilate cholesterol during growth in laboratory media had no effect on serum cholesterol in pigs on a high-cholesterol diet and a strain the actively assimilated cholesterol had a significant effect. The survival and growth of certain LAB having the ability to assimilate cholesterol in the intestine may be important in decreasing the absorption of dietary cholesterol from the digestive system to the blood and has the potential to aid in the control of serum and liver cholesterol. In this sense, acid and bile tolerance, and the ability to assimilate cholesterol were necessary factors that could affect the potential of probiotics to help control human serum cholesterol concentrations.

The main factor that determines the survival of bacteria upon passage through the stomach to the intestine is the $\mathrm{pH}$ of the gastric juice. Bacteria come in contact with low $\mathrm{pH}$ values, ranging from 2.0 to 8.0 in the stomach, depending upon whether or not food was being consumed simultaneously (Hood and Zottola, 1988). Survival at $\mathrm{pH} 3$ for 1.5 to $2 \mathrm{~h}$ is considered one standard for low-pH tolerance of probiotic bacteria (Itoh, 1992; Usman and Hosono, 1999), as ingestion with food or dairy products raises the $\mathrm{pH}$ in the stomach to 3.0 or higher (Martini et al., 1987). The 3 strains screened in this study showed high survival rare in artificial gastric juice at $\mathrm{pH} 3.0$ after a 3-h incubation, and they had similar levels of viability in artificial gastric juice. In vivo-surviving bacteria from the stomach would then contact bile in the small intestine. The relevant physiological concentrations of human bile ranged from $0.3 \%$ (Dunne et al., 1999) to 0.5\% (Dunne et al., 2001). It is generally considered necessary to evaluate the ability of potentially probiotic bacteria to resist the effects of bile. The 3 strains tested in this study showed similar bile salts tolerance when the concentrations of bile ranged from 0.3 to $0.5 \%$. These strains all had strong resistance even in the presence of $1 \%$ bile salts. The ability to uptake cholesterol in laboratory culture media has been shown for numerous lactobacilli, such as L. acidophilus, Lactobacillus delbrueckii ssp. bulgaricus, Lactobacillus casei, Lactobacillus gasseri, Lactobacillus

Table 4. Concentration of short-chain FA in the feces of rats fed a high-lipid diet alone (control) or supplemented with different lactic acid bacteria strains (LIP-1, MG9-2, or E7301) for $4 \mathrm{wk}$ (mg/g of dry wt) ${ }^{1}$

\begin{tabular}{lcccc}
\hline & & \multicolumn{3}{c}{ Treatment group } \\
\cline { 3 - 5 } FA & Control & LIP-1 & MG9-2 & E7301 \\
\hline Acetic acid & $41.5 \pm 2.90^{\mathrm{a}}$ & $47.67 \pm 3.30^{\mathrm{a}}$ & $42.60 \pm 5.18^{\mathrm{a}}$ & $44.07 \pm 3.52^{\mathrm{a}}$ \\
Propionic acid & $4.84 \pm 0.76^{\mathrm{c}}$ & $6.85 \pm 0.17^{\mathrm{ab}}$ & $7.64 \pm 0.33^{\mathrm{a}}$ & $6.19 \pm 0.19^{\mathrm{b}}$ \\
Butyric acid & $2.06 \pm 0.17^{\mathrm{c}}$ & $4.45 \pm 0.16^{\mathrm{a}}$ & $3.04 \pm 0.52^{\mathrm{b}}$ & $2.35 \pm 0.57^{\mathrm{bc}}$ \\
\hline
\end{tabular}

${ }^{\mathrm{a}-\mathrm{c}}$ Means within the same row followed by different superscript letters are significantly different $(P<0.05)$.

${ }^{1}$ Values are expressed as means \pm standard errors of the means; $\mathrm{n}=8$. 
reuteri, Lactobacillus amylovorus, and L. plantarum (Rašić et al., 1992; Buck and Gilliland, 1994; Tahri et al., 1996; Noh et al., 1997; de Roos et al., 1999; Hashimoto et al., 1999; Ha et al., 2006; Nguyen et al., 2007; Jeun et al., 2010). The 3 strains used in this study were all able to effectively assimilate cholesterol at varying levels.

Some reports (Gilliland et al., 1985; Danielson et al., 1989; Noh et al., 1997; Taranto et al., 1998; Nguyen et al., 2007) had indicated that in vitro experiments showed that strains of lactobacilli that were able to assimilate cholesterol were also able to reduce cholesterol in vivo. In this study, we selected 3 strains that had similar bile-salt resistance and low $\mathrm{pH}$ tolerance and in vitro variant cholesterol-assimilating properties to determine their cholesterol metabolism effects on rats fed a high-lipid diet. The 3 strains have shown cholesterol-reducing activity in in vitro experiments. Thus, we attempted to characterize their cholesterol-lowering effects in rats fed a high-fat and high-cholesterol diet with regard to their use as agents for improving serum, hepatic, and fecal lipid profiles.

The results showed that the 3 Lactobacillus strains were all effective in reducing serum total cholesterol, triglyceride, LDL cholesterol, and liver cholesterol while increasing the fecal excretion of total cholesterol, compared with the control group. Groups LIP-1 and MG92 expressed significantly $(P<0.05)$ lower cholesterol contents than group E7301. This was in agreement with the results in vitro where strains LIP-1 and MG9-2 exhibited greater amounts of cholesterol assimilated than E7301, whereas rats that were orally administered the LIP-1 or MG9-2 diets did not show significant differences. This was not consistent with the results in vitro in which strain LIP-1 exhibited significantly greater amounts of cholesterol assimilated than did MG9-2.

The cholesterol reduction produced by LAB can be explained by many mechanisms. It was hypothesized that intake of LAB increased HDL concentration. The increase of HDL is one of the factors determining a reduction in the risk of cardiovascular diseases (Assmann and Gotto, 2004). Low-density lipoprotein C is the main component of serum cholesterol. Therefore, lowering of the LDL-C level may be an important factor for decreasing serum total cholesterol levels. The present animal studies indicated a significant increase in the concentration of HDL cholesterol but a significant decrease in the concentrations of LDL cholesterol in the groups fed LIP-1 and MG9-2 in comparison with the control and E7301 groups. The increase in HDL may be important in controlling serum cholesterol concentrations due to its ability to remove surplus cholesterol from the blood stream to the liver (Rader, 2002; Shin et al., 2010). This may be a reason why rats in the LIP-1 and MG9-2 groups had lower serum cholesterol level than did rats in the E7301 group. Based on these findings, we conclude that the in vivo hypocholesterolemic effect of 3 strains may be due to their ability to increase HDL concentration. The results related to HDL and LDL cholesterol agreed with other findings (Fukushima and Nakao, 1995; Taranto et al., 1998; Hashimoto et al., 1999), which showed that animals fed with a diet rich in cholesterol had a reduction in total cholesterol levels and an increase in the HDL fraction with a daily intake of LAB or yogurt fermented with LAB.

Lactic acid bacteria might influence serum cholesterol by the promotion of fecal bile acid excretion (Begley et al., 2006; Lambert et al., 2008). It has been suggested that the promotion of fecal bile acid by LAB might be attributable to the deconjugation of bile and binding to bile acid in the small intestine (Tabuchi et al., 2004). Deconjugated bile acids have been found to be less absorbed from the small intestine than the conjugated bile acids (Jones et al., 2004). Thus, deconjugation of bile acids in the small intestine could result in greater excretion of bile acids from the intestinal tract, especially because free bile acids were excreted more rapidly than the conjugated bile acids (Chikai et al., 1987). In addition, LAB might inhibit the absorption of bile acid in the small intestine by binding of bile acid, stimulating bile acid excretion in feces (Tabuchi et al., 2004). An increased excretion of bile acids would decrease the amount of bile acids reaching the liver for secretion back into the intestine in the enterohepatic circulation. To maintain the necessary levels of conjugated bile acids for the enterohepatic circulation, excreted bile acids are replaced by synthesis of new ones in the body from cholesterol, thus providing the potential to reduce cholesterol in the body. Furthermore, free bile acids do not support the absorption of lipids, including cholesterol, from the intestines (De Rodas et al., 1996; Brashears et al., 1998). The present animal studies indicated that fecal total bile acid excretion was the highest in the group fed MG9-2 compared with the other groups. The difference among the control, LIP-1, and E7301 groups was not significant. From these results, it can be hypothesized that MG9-2 might cause higher preventing absorption of bile acid into the enterohepatic circulation, thus resulting in a decreased cholesterol concentration in the serum and liver and an increased cholesterol concentration in the feces. However, whether or not the administration of MG9-2 can actually affect the synthesis of bile acid in the liver needs to be further studied.

Serum total cholesterol reduction by assimilating and binding of cholesterol by LAB has been proposed as one of mechanisms for serum lipid improvement (Bottazzi et al., 1986; Hosono and Tonooka, 1995). Assimilating 
and binding of cholesterol by the bacterial cells likely would be less available for absorption from the intestine into blood. In this study, reduction in serum cholesterol by LIP-1 and E7301 might be related to this mechanism. Because the heat-killed cells of LIP-1 and E7301 showed higher cholesterol removal from media than that of MG9-2 (data not shown), it suggested that LIP1 and E7301 might inhibit the absorption of cholesterol in the small intestine due to their blinding action, resulting in significant reduction of serum cholesterol and enhancement of the fecal excretion of cholesterol. This mechanism is similar to those reported by Kimoto et al. (2002) and Liong and Shah (2006).

Probiotic bacteria, once resident in the host gut, ferment food-derived indigestible carbohydrates, which results in an increased production of SCFA. Many researchers believe that short SCFA, particularly propionate, might be involved in lowering cholesterol concentrations in serum and liver either by inhibiting hepatic cholesterol synthesis, or by redistributing cholesterol from plasma to the liver (Suzuki and Kajuu, 1983; Tabuchi et al., 2004). Nishina and Freedland (1990) have shown that propionate could inhibit the activity of pyruvate dehydrogenase in the liver and, thus, reduce the synthesis of FA. Trautwein et al. (1998) found that butyrate is known to inhibit liver cholesterol synthesis; meanwhile, propionate may inhibit the synthesis of FA in the liver, thereby lowering the rates of triacylglycerol secretion. Propionate is also involved in the control of hepatic cholesterol synthesis and it reduces the rate of cholesterol synthesis, which could lead to the lowering of plasma cholesterol levels (Trautwein et al., 1998). Chen et al. (1984) reported that the propionate generated by bacterial fermentation of fiber decreased cholesterol accumulation in both serum and liver of cholesterol-fed rats. The present animal studies indicated that the administration of 3 strains increased the production of fecal SCFA, particularly propionate and butyrate, compared with the control. Thus, we conclude that 3 strains might cause increased production of SCFA in the intestine, and the increased propionate and butyrate might inhibit the synthesis of FA and cholesterol in the liver, leading the cholesterol concentration in serum and liver to decrease. It must be noted that the concentrations of fecal propionate and butyrate in rats fed LIP-1 and MG9-2 were significantly increased compared with the E7301 group. This may partly explain that why rats in the LIP-1 and MG9-2 groups had lower serum and liver cholesterol levels than did rats in the E7301 group.

The precise mechanism of hypocholesterolemic activities caused by LAB has been difficult to explain. Based on these in vivo and in vitro finds, we conclude that the hypocholesterolemic effect by the 3 strains can be explained as follows: 1) the 3 strains fermented foodderived indigestible carbohydrates to produce SCFA in the gut, which caused a decrease in the systemic levels of blood lipids by inhibiting the synthesis of FA and cholesterol in the liver and 2) intake of the 3 strains increased HDL concentration in the serum, which could control serum cholesterol concentrations by removing surplus cholesterol from the blood stream to the liver. Moreover, we found that a good relationship between the in vivo hypocholesterolemic effect of the 3 strains and their ability to increase HDL concentration and propionate and butyrate concentrations. This may explain why rats in the LIP-1 and MG9-2 groups had lower serum and liver cholesterol levels than did rats in the E7301 group. In addition, reduction in serum cholesterol by LIP-1 and E7301 might be related to their ability to assimilate and bind cholesterol. Assimilating and binding of cholesterol by the bacterial cells likely would be less available for absorption from the intestine into blood. For MG9-2, the hypocholesterolemic effect seems to be related to the deconjugation of bile or binding to bile acid of the cells. To replace the excreted bile acids, more bile acids would have to be synthesized from cholesterol in the liver for secretion into the intestine in the enterohepatic circulation, thus providing the potential to reduce cholesterol in the body.

The 3 strains can lower serum cholesterol in multiple ways. Further studies will be required to determine the mechanism underlying the cholesterol-lowering effect in vitro and in vivo.

\section{CONCLUSIONS}

The 3 screened Lactobacillus strains had strong bile salt resistance, low $\mathrm{pH}$ tolerance, and variant hypocholesterolemic properties in vitro, and were able to reduce cholesterol in vivo. The 3 strains could reduce cholesterol levels in the serum and liver of rats via various mechanisms, which might be related to the increase in HDL in serum; the increase in SCFA concentrations in feces, particularly propionate and butyrate; the promotion of fecal bile acid excretion; and assimilation and binding of cholesterol by LAB. The mechanisms behind the hypocholesterolemic effect of 3 strains will need further investigation. The differences in cholesterol-lowering mechanisms in vivo among the 3 of strains might lead to the conclusion that a strain's ability to reduce cholesterol in vitro was not consistent with the results in vivo. These results indicated that the 3 strains may be promising candidates for use as probiotic cultures for lowering serum cholesterol levels.

\section{ACKNOWLEDGMENTS}

This research was supported by National Key Technologies R \& D Program (Beijing, China; Grant 
No.2009BADC1B01), the Innovation Research Team Development Program of Ministry of Education of China (Beijing, China; Grant No. IRT0967), the Earmarked fund for Modern Agro-industry Technology Research System (Beijing, China; Grant No. nycytx-0501), Natural Science Foundation of China (Beijing, China; Grant No. 30840011, 31160315), and Natural Science Foundation of Inner Mongolia (Huhhot, P. R. China; Grant No. 200508010406).

\section{REFERENCES}

Assmann, G., and A. M. Gotto Jr. 2004. HDL cholesterol and protective factors in atherosclerosis. Circulation 109:III8-III14.

Begley, M., C. Hill, and C. G. Gahan. 2006. Bile salt hydrolase activity in probiotics. Appl. Environ. Microbiol. 72:1729-1738.

Bliznakov, E. G. 2002. Lipid-lowering drugs (statins), cholesterol, and coenzyme Q10. The Baycol case-A modern Pandora's box. Biomed. Pharmacother. 56:56-59.

Bottazzi, V., C. Zacconi, E. Gonzaga, and M. Paladino. 1986. Absorption of cholesterol by intestinal lactic acid bacteria. Ann. Microbiol. 36:1-5.

Brashears, M. M., S. E. Gilliland, and L. M. Buck. 1998. Bile salt deconjugation and cholesterol removal from media by Lactobacillus casei. J. Dairy Sci. 81:2103-2110.

Buck, L. M., and S. E. Gilliland. 1994. Comparisons of freshly isolated strains of L. acidophilus of human intestinal origin for ability to assimilate cholesterol during growth. J. Dairy Sci. 77:2925-2933.

Chen, W. J. L., J. W. Anderson, and D. Jennings. 1984. Propionate may mediate the hypocholesterolemic effects of certain soluble plant fibers in cholesterol-fed rats. Proc. Soc. Exp. Biol. Med. $175: 215-218$

Chikai, T., H. Nakao, and K. Uchida. 1987. Deconjugation of bile acids by human intestinal bacteria implanted in germ-free rats. Lipids 22:669-671.

Danielson, A. D., E. R. Peo Jr., K. M. Shahani, A. J. Lewis, P. J. Whalen, and M. A. Amer. 1989. Anticholesterolemic property of Lactobacillus acidophilus yogurt fed to mature boars. J. Anim. Sci. $67: 966-974$.

De Rodas, B. Z., S. E. Gilliland, and C. V. Maxwell. 1996. Hypocholesterolemic action of Lactobacillus acidophilus ATCC 43121 and calcium in swine with hypercholesterolemia induced by diet. J. Dairy Sci. 79:2121-2128.

de Roos, N. M., G. Schouten, and M. B. Katan. 1999. Yoghurt enriched with Lactobacillus acidophilus does not lower blood lipids in healthy men and women with normal to borderline high serum cholesterol levels. Eur. J. Clin. Nutr. 53:277-280.

Dunne, C., L. Murphy, S. Flynn, L. O'Mahony, S. O'Halloran, M. Feeney, D. Morrissey, G. Thornton, G. Fitzgerald, C. Daly, B. Kiely, E. M. M. Quigley, G. C. O'Sullivan, F. Shanahan, and J. K. Collins. 1999. Probiotics: From myth to reality. Demonstration of functionality in animal models of disease and in human clinical trials. Antonie van Leeuwenhoek 76:279-292.

Dunne, C., L. O'Mahony, L. Murphy, G. Thornton, D. Morrissey, S. O'Halloran, M. Feeney, S. Flynn, G. Fitzgerald, C. Daly, B. Kiely, E. M. M. Quigley, G. C. O'Sullivan, F. Shanahan, and J. K. Collins. 2001. In vitro selection criteria for probiotic bacteria of human origin: Correlation with in vivo findings. Am. J. Clin. Nutr. 73:386S-392S.

Fedechko, I. M., R. I. Hrytsko, and B. A. Herasun. 1995. The antiimmunodepressive action of koumiss made from cow's milk. Lik. Sprava 9:104-106.

Folch, J., M. Lees, and G. H. Sloane-Stanley. 1957. A simple method for the isolation and purification of total lipids from animal tissues. J. Biol. Chem. 226:497-509.

Fradi, I., M. A. Drissa, M. Cheour, I. Meddeb, and H. Drissa. 2008. Coronary atherosclerosis and familial hypercholesterolemia: A case report. Tunis. Med. 86:200-202.
Friedewald, W. T., R. I. Levy, and D. S. Fredrickson. 1972. Estimation of the concentration of low-density lipoprotein cholesterol in plasma, without use of the preparative ultracentrifuge. Clin. Chem. 18:499-502

Fukushima, M., and M. Nakano. 1995. The effect of a probiotic on faecal and liver lipid classes in rats. Br. J. Nutr. 73:701-710.

Fuller, R. 1992. History and development of probiotics. Pages 1-8 in Probiotics - The Scientific Basis. R. Fuller, ed. Chapman and Hall, London, UK.

Gilliland, S. E., C. R. Nelson, and C. Maxwell. 1985. Assimilation of cholesterol by Lactobacillus acidophilus. Appl. Environ. Microbiol. 49:377-381.

Grunewald, K. K. 1982. Serum cholesterol levels in rats fed skim milk fermented by Lactobacillus acidophilus. J. Food Sci. 47:2078-2079.

Ha, C.-G., J.-K. Cho, C.-H. Lee, Y.-G. Chai, Y.-A. Ha, and S.-H. Shin. 2006. Cholesterol lowering effect of Lactobacillus plantarum isolated from human feces. J. Mol. Microbiol. Biotechnol. 16:1201-1209.

Hashimoto, H., K. Yamazaki, F. He, M. Kawase, M. Hosoda, and A. Hosono. 1999. Hypocholesterolemic effects of Lactobacillus casei ssp. casei TMC 0409 strain observed in the rats fed cholesterol contained diets. Anim. Sci. J. 72:90-97.

Hasisurong, Amuguleng, and Manglai. 2003. Koumiss and its medical value. Zhongguo Zhong Yao Za Zhi 28:11-14. (In Chinese).

Hood, S. K., and M. L. Zottola. 1988. Effect of low pH on the ability of Lactobacillus acidophilus to survive and adhere to human intestinal cell. J. Food Sci. 53:1514-1516.

Hosono, A., and T. Tonooka. 1995. Binding of cholesterol with lactic acid bacterial cells. Milchwissenschaft 50:556-560.

Itoh, T. 1992. Functional benefits from lactic acid bacteria used in cultured milk. Anim. Sci. Technol. (Jpn.) 63:1276-1289.

Jeun, J., S. Y. Kim, S.-Y. Cho, H.-J. Jun, H.-J. Park, J.-G. Seo, M.-J. Chung, and S.-J. Lee. 2010. Hypocholesterolemic effects of Lactobacillus plantarum KCTC3928 by increased bile acid excretion in C57BL/6 mice. Nutrition 26:321-330.

Jones, M. L., H. Chen, W. Ouyang, T. Metz, and S. Prakash. 2004. Microencapsulated genetically engineered Lactobacillus plantarum 80 (pCBH1) for bile acid deconjugation and its implication in lowering cholesterol. J. Biomed. Biotechnol. 2004:61-69.

Kimoto, H., S. Ohmomo, and T. Okamoto. 2002. Cholesterol removal from media by lactococci. J. Dairy Sci. 85:3182-3188.

Lambert, J. M., R. S. Bongers, W. M. de Vos, and M. Kleerebezem. 2008. Functional analysis of four bile salt hydrolase and penicillin acylase family members in Lactobacillus plantarum WCFS1. Appl. Environ. Microbiol. 74:4719-4726.

Liong, M. T., and N. P. Shah. 2006. Effects of a Lactobacillus casei synbiotic on serum lipoprotein, intestinal microflora, and organic acids in rats. J. Dairy Sci. 89:1390-1399.

Liu, L. 2007. Cardiovascular diseases in China. Biochem. Cell Biol. 85:157-163.

Locket, P. L., and D. D. Gallaher. 1989. An improved procedure for bile acid extraction and purification and tissue distribution in the rat. Lipids 24:221-223.

Lye, H.-S., G. Rusul, and M.-T. Liong. 2010a. Removal of cholesterol by lactobacilli via incorporation of and conversion to coprostanol. J. Dairy Sci. 93:1383-1392.

Lye, H.-S., G. Rusul Rahmat-Ali, and M.-T. Liong. 2010b. Mechanisms of cholesterol removal by lactobacilli under conditions that mimic the human gastrointestinal tract. Int. Dairy J. 20:169-175.

Martini, M. C., G. L. Bollweg, M. D. Levitt, and D. A. Savaiano. 1987. Lactose digestion by yogurt $\beta$-galactosidase: Influence of $\mathrm{pH}$ and microbial cell integrity. Am. J. Clin. Nutr. 45:432-436.

Mashige, F., N. Tanaka, A. Maki, S. Kamei, and M. Yamanaka. 1981. Direct spectrophotometry of total bile acids in serum. Clin. Chem. $27: 1352-1356$

Nguyen, T. D. T., J. H. Kang, and M. S. Lee. 2007. Characterization of Lactobacillus plantarum $\mathrm{PH} 04$, a potential probiotic bacterium with cholesterol-lowering effects. Int. J. Food Microbiol. 113:358-361.

Nielson, J. W. and S. E. Gilliland. 1985. Variations in cholesterol assimilation by individual strains of Lactobacillus acidophilus and 
Lactobacillus casei from human intestines. J. Dairy Sci. 68(Suppl. 1):83. (Abstr.)

Nishina, P. M., and R. Freedland. 1990. Effects of propionate on lipid biosynthesis in isolated rat hepatocytes. J. Nutr. 120:668-673.

Noh, D. O., S. H. Kim, and S. E. Gilliland. 1997. Incorporation of cholesterol into the cellular membrane of Lactobacillus acidophilus ATCC 43121. J. Dairy Sci. 80:3107-3113.

Rader, D. J. 2002. High density lipoproteins and atherosclerosis. Am. J. Cardiol. 90:62i-70i.

Rašić, J. L., I. F. Vujičić, M. Škrinjar, and M. Vulić. 1992. Assimilation of cholesterol by some cultures of lactic acid bacteria and bifidobacteria. Biotechnol. Lett. 14:39-44.

Rudel, L. L., and M. D. Morris. 1973. Determination of cholesterol using o-phthalaldehyde. J. Lipid Res. 14:364-366.

Shin, H. S., S. Y. Park, D. K. Lee, S. A. Kim, H. M. An, J. R. Kim, M. J. Kim, M. G. Cha, S. W. Lee, K. J. Kim, K. O. Lee, and N. J. Ha. 2010. Hypocholesterolemic effect of sonication-killed Bifidobacterium longum isolated from healthy adult Koreans in high cholesterol fed rats. Arch. Pharm. Res. 33:1425-1431.

Stoianova, L. G., L. A. Abramova, and K. S. Ladodo. 1988. Sublimation-dried mare's milk and the possibility of its use in creating infant and dietary food products. Vopr. Pitan. 3:64-67.

Suzuki, M., and T. Kajuu. 1983. Suppression of hepatic lipogenesis by pectin and galacturonic acid orally-fed at the separate timing from digestion-absorption of nutrients in rats. J. Nutr. Sci. Vitaminol. (Tokyo) 29:553-562.

Tabuchi, M., A. Tamura, N. Yamada, T. Ishida, M. Hosoda, and A. Hosono. 2004. Hypocholesterolemic effects of viable and heat-sterilized cells of Lactobacillus GG in rats fed a high-cholesterol diet. Milchwissenschaft 59:249-253.
Tahri, K., J. P. Grill, and F. Schneider. 1996. Bifidobacteria strain behavior towards cholesterol: Coprecipitation with bile salts and assimilation. Curr. Microbiol. 33:187-193.

Taranto, M. P., M. Medici, G. Perdigon, A. P. Ruiz Holdago, and G. F. Valdez. 1998. Evidence for hypocholesterolemic effect of Lactobacillus reuteri in hypercholesterolemic mice. J. Dairy Sci. 81:2336-2340.

Tortuero, F., A. Brenes, and J. Riopérez. 1975. The influence of intestinal (ceca) flora on serum and egg yolk cholesterol levels in laying hens. Poult. Sci. 54:1935-1938.

Trautwein, E. A., D. Rieckhoff, and H. F. Erbersdobler. 1998. Dietary inulin lowers plasma cholesterol and triacylglycerol and alters biliary bile acid profile in hamsters. J. Nutr. 128:1937-1943.

Tsenina, V. S., and V. M. Frolov. 1980. Use of koumiss made from cow's milk in liver diseases. Med. Sestra 39:29-30.

Usman, , and A. Hosono. 1999. Bile tolerance, taurocholate deconjugation and binding of cholesterol by Lactobacillus gasseri strains. J Dairy Sci. 82:243-248.

Usman, , and A. Hosono. 2000. Effect of administration of Lactobacillus gasseri on serum lipids and fecal steroids in hypercholesterolemic rats. J. Dairy Sci. 83:1705-1711.

Vinderola, G. C., and A. J. Reinheimer. 2003. Lactic acid starter and probiotic bacteria: A comparative "in vitro" study of probiotic characteristics and biological barrier resistance. Food Res. Int 36:895-904.

WHO (World Health Organization). 2009. Cardiovascular disease; Fact sheet No. 317. WHO, Geneva, Switzerland. Accessed May 19, 2010. http://www.who.int/mediacentre/factsheets/fs317/en/ print.html. 